\title{
Effects of the Novel Fungicide Benzothiostrobin on Sclerotinia sclerotiorum in the Laboratory and on Sclerotinia Stem Rot in Rape Fields
}

Congying Xu, Xiaoyu Liang, Yiping Hou, and Mingguo Zhou, College of Plant Protection, Nanjing Agricultural University, Key Laboratory of Pesticide, Nanjing 210095, China

\begin{abstract}
Xu, C., Liang, X., Hou, Y., and Zhou, M. 2015. Effects of the novel fungicide benzothiostrobin on Sclerotinia sclerotiorum in the laboratory and on Sclerotinia stem rot in rape fields. Plant Dis. 99:969-975.

We determined the effects and efficacy of benzothiostrobin, a new strobilurin-derived fungicide, against the plant-pathogenic fungus Sclerotinia sclerotiorum (the causal agent of Sclerotinia stem rot). Mycelial growth and sclerotial germination in vitro were strongly inhibited by benzothiostrobin in the presence of salicylhydroxamic acid. On detached rapeseed leaves, benzothiostrobin at $40 \mu \mathrm{g} / \mathrm{ml}$ reduced lesion development by $87 \%$. No cross-resistance was detected between

benzothiostrobin and carbendazim, iprodione, fludioxonil, or boscalid. A formulated mixture of benzothiostrobin and fluazinam at 1:1 had synergistic activity against $S$. sclerotiorum in vitro. In field trials, benzothiostrobin alone or formulated with fluazinam at 1:1 $\left(150 \mathrm{~g}\right.$ a.i. $\left.\mathrm{ha}^{-1}\right)$ was significantly $(P<0.05)$ superior to iprodione in controlling Sclerotinia stem rot of rapeseed. These results suggest that benzothiostrobin has substantial potential for the control of Sclerotinia stem rot.
\end{abstract}

Sclerotinia sclerotiorum (Lib.) de Bary is a necrotrophic plant pathogen with a worldwide distribution and a broad host range. The fungus can infect $>405$ plant species, including economically important crops such as rapeseed, sunflower, lettuce, and soybean. These and other crops routinely suffer substantial losses due to $S$. sclerotiorum $(4,7)$. The fungus causes Sclerotinia stem rot of rapeseed, which is a very damaging disease that occurs in all rapeseedgrowing areas in China and especially in the area of the Yangtze River. The average incidence of Sclerotinia stem rot of rapeseed in this region was estimated at 10 to $20 \%$ but can be as high as $80 \%$ (17).

At present, application of fungicides is the principal tool for controlling Sclerotinia diseases on most crops $(5,27)$. However, the extensive use of benzimidazole fungicides (carbendazim) and dicarboximide fungicides (iprodione or dimethachlon) has selected for resistant individuals and resulted in control failures $(20,25,36)$. Therefore, it is necessary to find more effective fungicides with contrasting modes of action to replace the compounds that are currently used to control Sclerotinia stem rot. It is also important to screen mixtures of fungicides with different modes of action in order to minimize selection for fungicide resistance and to increase disease control. In the present study, we investigated the potential of a new fungicide, benzothiostrobin, for the control of S. sclerotiorum.

The strobilurin fungicides are a class of fungicidal compounds modeled after natural compounds isolated from several Basidiomycetes species that inhabit decaying plant material in woodland soils (3). Their mode of action is to inhibit electron transport between cytochrome $b$ and cytochrome $c l$ in the mitochondrial respiratory chain, leading to disruption of the production of ATP $(3,6)$. Benzothiostrobin [(E)-2-[2-(5-methoxy-benzothiazol-2-methylthio) phenyl]-3-methoxyacrylate] (Fig. 1; development code number: Y5247) is a novel strobilurin fungicide that was developed by the Key Laboratory of Pesticide \& Chemical Biology of Ministry of Education, Central China Normal University. Our previous study showed that benzothiostrobin had a strong antifungal activity against S. sclerotiorum in vitro (34).

Corresponding author: M. G. Zhou; E-mail: mgzhou@njau.edu.cn

Accepted for publication 10 January 2015.

http://dx.doi.org/10.1094/PDIS-09-14-0983-RE

C 2015 The American Phytopathological Society
In the current study, we determined how benzothiostrobin performed when combined with fluazinam. Fluazinam is a protective fungicide and belongs to the phenylpyridinamine group of chemicals. It has a broad spectrum of activity and is effective against diseases caused by species of Sclerotinia, Botrytis, Alternaria, and Phytophthora (2).

To our knowledge, the use of benzothiostrobin alone or in combination with fluazinam for control of Sclerotinia stem rot has not been previously reported. Therefore, the objectives of this study were to (i) obtain more information concerning how benzothiostrobin inhibits $S$. sclerotiorum, (ii) determine whether there is cross-resistance between benzothiostrobin and other fungicides, (iii) determine the optimum ratio of benzothiostrobin and fluazinam for inhibiting mycelial growth of $S$. sclerotiorum, and (iv) determine the efficacy of benzothiostrobin alone and in combination with fluazinam for controlling Sclerotinia stem rot of rapeseed in the field.

\section{Materials and Methods}

Fungicides, media, and isolates. Stock solutions of the following fungicides were prepared by dissolving them in methanol to $10^{4}$ or $10^{5} \mu \mathrm{g} / \mathrm{ml}$ : technical-grade benzothiostrobin (a.i. 97\%; Central China Normal University), azoxystrobin (a.i. 97.8\%; Syngenta China Co., Ltd., China), fluazinam (a.i. 97.5\%; Suli Chemical Co., Ltd., China), iprodione (a.i. 96.2\%; Wenzhou Pesticide Factory, China), fludioxonil (a.i. 97.9\%; Syngenta Biotechnology Co. Ltd.), boscalid (a.i. 98.4\%; BASF Co., China) and salicylhydroxamic acid (SHAM) (a.i. 99\%; Sigma China Co., Ltd., China). Technical-grade carbendazim (MBC) (a.i. 98\%; Shenyang Study Institute of Chemical Industry, China) was dissolved in $0.1 \mathrm{~N} \mathrm{HCl}$ to make a stock solution of $10^{4} \mu \mathrm{g} / \mathrm{ml}$. Iprodione (50\% WP), fluazinam (40\% SC), and benzothiostrobin (5\% EC) were purchased in Nanjing. The fungicides were stored at $4^{\circ} \mathrm{C}$ in the dark.

Alkyl ester agar (AEA) medium contained $5 \mathrm{~g}$ of yeast extract, $6 \mathrm{~g}$ of $\mathrm{NaNO}_{3}, 1.5 \mathrm{~g}$ of $\mathrm{KH}_{2} \mathrm{PO}_{4}, 0.5 \mathrm{~g}$ of $\mathrm{KCl}, 0.25 \mathrm{~g}$ of $\mathrm{MgSO}_{4}, 20 \mathrm{ml}$ of glycerin, and $20 \mathrm{~g}$ of agar per liter of distilled water. Alkyl ester broth (AEB) medium was identical to AEA medium except that it lacked agar. Potato dextrose agar (PDA) was prepared with $200 \mathrm{~g}$ of potato, $20 \mathrm{~g}$ of dextrose, and $20 \mathrm{~g}$ of agar per liter of distilled water.

All 24 isolates of $S$. sclerotiorum used in this study were collected from oilseed rape fields in Jiangsu Province of China or were derived from isolates collected from field. Their relevant characteristics are listed in Table 1. The isolates that were collected from field were tested for sensitivity to MBC on PDA by the discriminatory dosage 
method $(18,19)$; isolates that showed normal growth with MBC at $5 \mu \mathrm{g} / \mathrm{ml}$ were considered resistant to $\mathrm{MBC}$, while isolates that were completely inhibited were considered sensitive to MBC (Table 1). The following fungicide-resistant isolates, which were collected from the field or induced in our laboratory, were used to determine cross-resistance: JK19R1, JK19R2, and NT16R1 are resistant to boscalid (32); SZ10R and HA61R are resistant to fludioxonil $(9,14)$; ZJ288-1 and CZ138-1 are resistant to iprodione (31); and HA4D and XH17D are resistant to MBC (collected from field). The others were used to determine the inhibitory activity of benzothiostrobin or synergistic interaction of benzothiostrobin and fluazinam in mixture. These isolates were maintained on PDA slants in airtight centrifuge tubes at $4^{\circ} \mathrm{C}$.

Mycelial growth of $S$. sclerotiorum as affected by benzothiostrobin. The effect of benzothiostrobin on in vitro mycelial growth of S. sclerotiorum was determined on agar and in shake culture. The experiment on agar used isolates WX7S, XH1S, SA2D, and HA22D. Plugs (5 $\mathrm{mm}$ in diameter) from the leading edge of an actively growing colony were transferred to a series of AEA plates containing benzothiostrobin at $0,0.00780 .015625,0.03125$, $0.0625,0.125,0.25$, or $0.5 \mu \mathrm{g} / \mathrm{ml}$. The plates were also amended or not amended with SHAM at $50 \mu \mathrm{g} / \mathrm{ml}$; SHAM was included in order to inhibit the alternative respiratory pathway $(23,31)$. This experiment also included azoxystrobin as a standard, with and without SHAM, at the same concentrations used for benzothiostrobin. Azoxystrobin was used as a standard because a previous study showed that it is extremely effective against $S$. sclerotiorum (10). Each treatment was represented by three replicate plates. Colony diameters were measured after 2 days of incubation at $25^{\circ} \mathrm{C}$ in

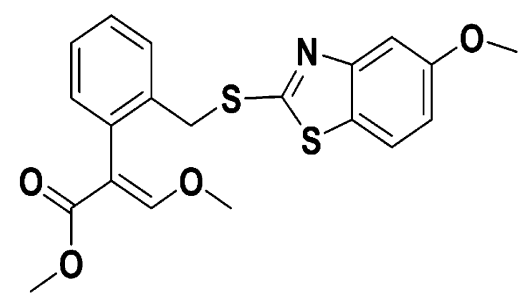

Fig. 1. Chemical structure of benzothiostrobin.

Table 1. Isolates of Sclerotinia sclerotiorum used in this study

\begin{tabular}{lll}
\hline Isolate & \multicolumn{1}{c}{ Characteristic } & \multicolumn{1}{c}{ Source of material } \\
\hline WX7S & Wild type & Oilseed rape field in Jiangsu Province \\
XH1S & Wild type & Oilseed rape field in Jiangsu Province \\
SA2D & MBC resistant & Oilseed rape field in Jiangsu Province \\
HA22D & MBC resistant & Oilseed rape field in Jiangsu Province \\
NT41S & Wild type & Oilseed rape field in Jiangsu Province \\
LYG112S & Wild type & Oilseed rape field in Jiangsu Province \\
YZ6S & Wild type & Oilseed rape field in Jiangsu Province \\
JK19 & Wild type & Oilseed rape field in Jiangsu Province \\
NT16 & Wild type & Oilseed rape field in Jiangsu Province \\
JK19R1 & Boscalid resistant & Induced in laboratory \\
JK19R2 & Boscalid resistant & Induced in laboratory \\
NT16R1 & Boscalid resistant & Induced in laboratory \\
SZ10S & Wild type & Oilseed rape field in Jiangsu Province \\
HA61S & Wild type & Oilseed rape field in Jiangsu Province \\
SZ10R & Fludioxonil resistant & Induced in laboratory \\
HA61R & Fludioxonil resistant & Induced in laboratory \\
ZJ288-1 & Iprodione resistant & Induced in laboratory \\
CZ138-1 & Iprodione resistant & Induced in laboratory \\
HA4D & MBC resistant & Oilseed rape field in Jiangsu Province \\
XH17D & MBC resistant & Oilseed rape field in Jiangsu Province \\
WX1S & Wild type & Oilseed rape field in Jiangsu Province \\
XH8D & MBC resistant & Oilseed rape field in Jiangsu Province \\
YZ10S & Wild type & Oilseed rape field in Jiangsu Province \\
NY28S & Wild type & Oilseed rape field in Jiangsu Province \\
\hline & &
\end{tabular}

darkness. Growth inhibition, expressed as a percentage of the control (plates without fungicide), was calculated. The median effective benzothiostrobin and azoxystrobin concentrations $\left(\mathrm{EC}_{50}\right.$ values) were calculated based on linear regression of colony diameter on log-transformed fungicide concentration (28). The experiment was performed twice.

The experiment in shake culture (broth) used three randomly selected S. sclerotiorum isolates: NT41S, LYG112S, and SA2D. Ten mycelial plugs ( $5 \mathrm{~mm}$ in diameter) were transferred to a $250-\mathrm{ml}$ conical flask containing $100 \mathrm{ml}$ of AEB with benzothiostrobin at $0.015 \mu \mathrm{g} / \mathrm{ml}$ and SHAM at $50 \mu \mathrm{g} / \mathrm{ml}$ or with azoxystrobin at $0.015 \mu \mathrm{g} / \mathrm{ml}$ (as a standard) and SHAM at $50 \mu \mathrm{g} / \mathrm{ml}$. Cultures without benzothiostrobin or azoxystrobin but with SHAM were used as the control. After the flasks were shaken at $175 \mathrm{rpm}$ and $25^{\circ} \mathrm{C}$ for 3 days, the mycelia were harvested, washed three times with distilled water, dried at $80^{\circ} \mathrm{C}$ for $8 \mathrm{~h}$, and weighed. The percentage of growth inhibition was determined based on mycelial dry weight relative to that of the control. Each treatment was represented by three replicate flasks. The experiment was performed twice.

Sclerotial germination as affected by benzothiostrobin. Sclerotia were produced by growing isolates SA2D and LYG112S on PDA at $20^{\circ} \mathrm{C}$. After 2 weeks, the sclerotia were gently harvested, surface disinfested in $0.5 \% \mathrm{NaOCl}$ for $3 \mathrm{~min}$, rinsed three times with sterile distilled water, and dried with sterilized filter paper at room temperature. Then, sclerotia ( 3 to $5 \mathrm{~mm}$ in diameter) were imbedded in the agar in 9-cm-diameter petri dishes (five sclerotia per dish) containing $20 \mathrm{ml}$ of AEA with benzothiostrobin or azoxystrobin (as a standard) at $0,0.5,1,2$, or $5 \mu \mathrm{g} / \mathrm{ml}$ and with SHAM at $50 \mu \mathrm{g} / \mathrm{ml}$. Four of the sclerotia in each dish were spaced at equal intervals along the edge of the agar, and one was placed in the center. Twenty sclerotia were used in each treatment. Each treatment was represented by three replicate groups. The dishes were incubated at $25^{\circ} \mathrm{C}$. Sclerotia were examined under a light microscope for myceliogenic germination and hyphal growth after 3,4 , and 5 days. Sclerotia that produced hyphae $\geq 2 \mathrm{~mm}$ long were considered to have germinated. Inhibition of sclerotial germination was calculated as previously described (13). The experiment was performed twice.

Efficacy of benzothiostrobin on rapeseed leaves. Benzothiostrobin inhibition of $S$. sclerotiorum on rapeseed leaves was determined using previously described methods $(15,31)$. Fully expanded leaves of the same age and area were excised from greenhouse-grown oilseed rape plants ('Ningyou 16' from Jiangsu Fengqing Seed Science Company). The leaves were surface disinfested in $0.5 \%$ sodium hypochlorite for $1 \mathrm{~min}$, rinsed three times with sterile distilled water, blotted with sterile filter paper to remove excess water, and allowed to dry. The benzothiostrobin stock solution was diluted with distilled water containing $0.1 \%$ Tween 80 to obtain benzothiostrobin at $0,5,10,20$, and $40 \mu \mathrm{g} / \mathrm{ml}$; these solutions were applied to the leaves as a spray. Azoxystrobin at $20 \mu \mathrm{g} / \mathrm{ml}$ was included as a standard. Mycelial plugs (5 $\mathrm{mm}$ in diameter, from PDA plate) of $S$. sclerotiorum isolate YZ6S were placed on detached leaves when the leaves were dry. The leaves were maintained on moistened filter papers in a $20-\mathrm{cm}$-diameter petri dish, and the dishes were kept at $25^{\circ} \mathrm{C}$ with a 16 -h photoperiod and $80 \%$ relative humidity. After 3 days, lesion size was determined by taking the mean of two diameters that were measured at a right angle to each other. Disease control was calculated as follows (14): disease control $=($ lesion diameter in the water control - lesion diameter in the treatment)/ lesion diameter in the water control $\times 100$. Each treatment was represented by 10 replicate leaves, and the experiment was performed three times.

Cross-resistance. To determine cross-resistance between benzothiostrobin and fungicides that have been extensively used to control Sclerotinia stem rot in China, wild-type fungicide-sensitive isolates of S. sclerotiorum and isolates resistant to iprodione (a dicarboximide fungicide), fludioxonil (a phenylpyrrole fungicide), boscalid (a carboxamide fungicide), or carbendazim (a benzimidazole fungicide) were assessed for sensitivity to benzothiostrobin. The Fungicide Resistance Action Committee rates these as medium to high resistance risk and places them in resistance groups 2 for iprodione, 12 
for fludioxonil, 7 for boscalid, 9 for cyprodinil, and 1 for carbendazim (11). Mycelial plugs (5 $\mathrm{mm}$ in diameter) were transferred from the margins of PDA colonies to PDA or AEA plates containing a series of concentrations of iprodione, fludioxonil, boscalid, carbendazim, or benzothiostrobin. Each concentration of each fungicide was represented by three replicate plates, and the experiment was performed three times. The plates were incubated for 2 to 3 days at $25^{\circ} \mathrm{C}$ in the dark, and the $\mathrm{EC}_{50}$ values were determined as described above.

Synergistic in vitro inhibition of $S$. sclerotiorum by mixtures containing different proportions of benzothiostrobin and fluazinam. Mycelial plugs ( $5 \mathrm{~mm}$ in diameter) were removed from the edge of a 2-day-old colony of isolate WX1S growing on PDA. The plugs were placed face up in the center of a petri dish $(9 \mathrm{~cm}$ in diameter) containing AEA with benzothiostrobin alone, fluazinam alone, or mixtures containing various concentrations of both fungicides. The mixtures were prepared at ratios (benzothiostrobin/ fluazinam [vol/vol]) of $6: 1,4: 1,2: 1,1: 1,1: 2,1: 4$, and 1:6. The solutions were then diluted to obtain a series of concentrations. The final concentrations for fluazinam alone were $0,0.00625,0.0125,0.025$, 0.05 , and $0.1 \mu \mathrm{g} / \mathrm{ml}$. The final concentrations for benzothiostrobin alone or in mixture with fluazinam were $0,0.0039,0.0078$, $0.015625,0.03125,0.0625$, and $0.125 \mu \mathrm{g} / \mathrm{ml}$. SHAM at $50 \mu \mathrm{g} / \mathrm{ml}$ was also added to the AEA plates amended with benzothiostrobin or the mixtures including control. Each concentration of each treatment was represented by four replicate plates. After the plates were incubated for about 2 days at $25^{\circ} \mathrm{C}$ in the dark, the $\mathrm{EC}_{50}$ values were determined as described earlier. The experiment was performed twice.

The synergy ratio (SR) of fungicide mixtures was calculated according to Wadley (29) and Gisi et al. (12). The $\mathrm{EC}_{50 \text { (th) }}$ values, which are the theoretical $\mathrm{EC}_{50}$ values of the mixtures, were calculated as follows: $\mathrm{EC}_{50(\text { th })}=(a+b) /\left(a / \mathrm{EC}_{50(A)}+b / \mathrm{EC}_{50(B)}\right)$, where $A$ and $B$ represent the individual components of the mixture, and $a$ and $b$ represent the ratios of these components in the mixtures. SR was calculated as $\mathrm{SR}=\mathrm{EC}_{50(\mathrm{th})} / \mathrm{EC}_{50 \text { (me) }}$, where $\mathrm{EC}_{50(\mathrm{me})}$ values are the measured $\mathrm{EC}_{50}$ values of the mixtures.

An $\mathrm{SR}<0.5$ indicates antagonistic interactions between the fungicides in mixture, an SR between 0.5 and 1.5 indicates additive interactions, and an SR $>1.5$ indicates synergistic interactions.

Variation among isolates in their response to the optimal mixture of benzothiostrobin and fluazinam. The response of six S. sclerotiorum isolates from different areas of Jiangsu Province to the optimal mixture of benzothiostrobin and fluazinam (i.e., the mixture with the largest SR value as determined in the previous section) was determined. AEA medium was amended with benzothiostrobin alone, fluazinam alone, or the optimal mixture (which was 1:1; see Results) at a series of concentrations, as described in the previous section. SHAM at $50 \mu \mathrm{g} / \mathrm{ml}$ was added to the AEA plates amended with benzothiostrobin or the mixtures including control. $\mathrm{EC}_{50}$ values were determined and SR values were calculated as described above. Each concentration was represented by four replicate plates, and the experiment was repeated.

Effect of the optimal mixture of benzothiostrobin and fluazinam on mycelial growth over time. Fresh mycelial plugs ( $5 \mathrm{~mm}$ diameter) from the edge of a 2-day-old colony (isolate WX1S) on PDA were transferred to AEA plates containing benzothiostrobin, fluazinam, or the optimal mixture at $0.01 \mu \mathrm{g} / \mathrm{ml}$ (1:1; see Results). SHAM at $50 \mu \mathrm{g} / \mathrm{ml}$ was also added to all plates with benzothiostrobin and the mixture. Plates without fungicide or SHAM or with SHAM alone served as controls. After $12,24,48$, or $54 \mathrm{~h}$ at $25^{\circ} \mathrm{C}$, colony diameters (minus the diameter of the inoculation plug) were measured, and growth inhibition as a percentage of the controls was calculated. Each treatment was represented by four replicate plates, and the experiment was performed two times.

Control of Sclerotinia stem rot by benzothiostrobin alone and a 1:1 mixture of benzothiostrobin and fluazinam in the field. The control efficacy of different treatments with benzothiostrobin and fluazinam on Sclerotinia stem rot was evaluated under field conditions. The field trials were conducted in two oilseed rape fields (about $1 \mathrm{~km}$ away from each other) in Jiangyan, Jiangsu Province in 2014. The soil type in fields is classified as clay loam. Ningyou 16 oilseed rape is a hybrid of 'Yangyou 1' and 'Zhen 8901'. Planting date was in mid-September 2013 and planting density was 25,000 plants/acre.

Each field was divided into 33 plots; each plot was 4 by $5 \mathrm{~m}^{2}$. Eleven treatments with three replicates were arranged in a completely randomized design. The treatments were (i) water control, 750 liters $\mathrm{ha}^{-1}$ (ii); iprodione (50\% WP), $150 \mathrm{~g}$ a.i. ha ${ }^{-1}$; (iii) benzothiostrobin (5\% EC), $75 \mathrm{~g}$ a.i. $\mathrm{ha}^{-1}$; (iv) benzothiostrobin, $112.5 \mathrm{~g}$ a.i. ha $\mathrm{h}^{-1}$; (v) benzothiostrobin, $150 \mathrm{~g}$ a.i. ha ${ }^{-1}$; (vi) fluazinam (40\% SC), $75 \mathrm{~g}$ a.i. $\mathrm{ha}^{-1}$; (vii) fluazinam, $112.5 \mathrm{~g}$ a.i. $\mathrm{ha}^{-1}$; (viii) fluazinam, $150 \mathrm{~g}$ a.i. $\mathrm{ha}^{-1}$; (ix) a 1:1 mixture of benzothiostrobin and fluazinam, $75 \mathrm{~g}$ a.i. $\mathrm{ha}^{-1}$; (x) a 1:1 mixture of benzothiostrobin and fluazinam, $112.5 \mathrm{~g} \mathrm{a.i.} \mathrm{ha}^{-1}$; and (xi) a 1:1 mixture of benzothiostrobin and fluazinam, $150 \mathrm{~g}$ a.i. $\mathrm{ha}^{-1}$. Fungicides, which were applied as foliar sprays with a Jacto HeavyDuty HD400 sprayer (Agrolex, Singapore), were applied twice, with 7 days between sprays, when $90 \%$ of the major stems were flowering. On 27 March 2014, the first fungicide application was conducted. No other fungicides were applied. About 1 week before harvest, disease severity was assessed in both experiments by examining 120 randomly selected plants in each plot for Sclerotinia stem rot. Severity was assessed using the following scale: $0=$ no lesions, $1=$ lesions on $<5 \%$ of the tem, $3=$ lesions on 6 to $15 \%$ of the stem, $5=$ lesions on 16 to $30 \%$ of the stem, $7=$ lesions on 31 to $50 \%$ of the stem, and $9=$ lesions on $>50 \%$ of the stem $(30,35)$.

Statistical analysis. Statistical Package for the Social Science (SPSS 14.0; SPSS Inc., Chicago) and SAS 9.2 (SAS Institute, Cary, NC) were used for statistical analysis. The analysis of variance procedure of SPSS and Fisher's least significant difference $(P=0.05)$ were used to determine significant differences between treatments. Data of field test were analyzed nonparametrically using Proc Mixed of SAS, and relative treatment effects and their confidence intervals were calculated using the LD_CI macro (24). Cross-resistance between fungicides was analyzed using Spearman's rank correlation coefficient for the log-transformed $\mathrm{EC}_{50}$ values.

\section{Results}

Sensitivity of mycelial growth of $S$. sclerotiorum to benzothiostrobin. Based on $\mathrm{EC}_{50}$ values, the inhibition of mycelial growth of four $S$. sclerotiorum isolates by benzothiostrobin and azoxystrobin (the standard) was greater with SHAM than without SHAM (Table 2). Among the four isolates, the $\mathrm{EC}_{50}$ values of benzothiostrobin with SHAM ranged from 0.014 to $0.029 \mu \mathrm{g} / \mathrm{ml}$, with a mean $0.021 \mu \mathrm{g} / \mathrm{ml}$. The $\mathrm{EC}_{50}$ values of azoxystrobin with SHAM ranged from 0.050 to $0.118 \mu \mathrm{g} / \mathrm{ml}$, with a mean of $0.077 \mu \mathrm{g} / \mathrm{ml}$. Although there was

Table 2. Effect of benzothiostrobin and azoxystrobin \pm salicylhydroxamic acid (SHAM) on mycelial growth of Sclerotinia sclerotiorum on agar

\begin{tabular}{lcccc}
\hline & \multicolumn{4}{c}{$\mathbf{E C}_{\mathbf{5 0}}(\boldsymbol{\mu} \mathbf{g} / \mathbf{m l})^{\mathbf{z}}$} \\
\cline { 2 - 5 } Fungicide & Isolate WX7S & Isolate XH1S & Isolate SA2D & Isolate HA22D \\
\hline Benzothiostrobin (-SHAM) & $0.360 \pm 0.036 \mathrm{~b}$ & $0.649 \pm 0.010 \mathrm{a}$ & $0.249 \pm 0.024 \mathrm{~b}$ & $0.401 \pm 0.049 \mathrm{~b}$ \\
Benzothiostrobin (+SHAM) & $0.014 \pm 0.001 \mathrm{c}$ & $0.026 \pm 0.004 \mathrm{~b}$ & $0.014 \pm 0.001 \mathrm{c}$ & $0.029 \pm 0.019 \mathrm{c}$ \\
Azoxystrobin (-SHAM) & $0.879 \pm 0.189 \mathrm{a}$ & $0.664 \pm 0.133 \mathrm{a}$ & $1.330 \pm 0.452 \mathrm{a}$ & $0.949 \pm 0.158 \mathrm{a}$ \\
Azoxystrobin (+SHAM) & $0.050 \pm 0.002 \mathrm{bc}$ & $0.075 \pm 0.008 \mathrm{~b}$ & $0.065 \pm 0.007 \mathrm{c}$ & $0.118 \pm 0.040 \mathrm{c}$ \\
\hline
\end{tabular}

${ }^{\mathrm{z}} \mathrm{EC}_{50}=$ effective concentration causing $50 \%$ mycelial growth inhibition. Values are means \pm standard deviations. Means in a column followed by the same letter are not different according to Fisher's least significant difference test $(P=0.05)$. 
no significant statistics difference between benzothiostrobin and azoxystrobin on the $\mathrm{EC}_{50}$ values against $S$. sclerotiorum, benzothiostrobin was more effective on the inhibition of mycelial growth than azoxystrobin at the same concentration (Fig. 2A).

Benzothiostrobin also greatly decreased the dry weight of mycelium of $S$. sclerotiorum isolates growing in AEB liquid medium (Fig. 2B and C). Inhibition in the liquid medium was greater with benzothiostrobin than with azoxystrobin (Fig. 2C).

Effect of benzothiostrobin on sclerotial germination. Benzothiostrobin inhibition of germination of S. sclerotiorum sclerotia on agar increased with benzothiostrobin concentration. The highest concentration tested $(5 \mu \mathrm{g} / \mathrm{ml})$ strongly inhibited sclerotial germination and mycelial growth from sclerotia (Table 3). Inhibition of sclerotial germination by benzothiostrobin was comparable with that by azoxystrobin.
Efficacy of benzothiostrobin on detached rapeseed leaves. The control of $S$. sclerotiorum on detached rapeseed leaves increased with the concentration of benzothiostrobin (Table 4). At $20 \mu \mathrm{g} / \mathrm{ml}$, benzothiostrobin and azoxystrobin provided similar levels of control.

Cross-resistance. Depending on $\mathrm{EC}_{50}$ values, all S. sclerotiorum strains which were sensitive or resistant to the commonly used fungicides iprodione, fludioxonil, boscalid, or carbendazim, were sensitive to benzothiostrobin (Table 5). Spearman rank correlations for cross-resistance between benzothiostrobin and other fungicides were analyzed. The values of Spearman's $\rho\left(r_{s}\right)$ for iprodione, fludioxonil, boscalid, or carbendazim were 0.664 , $0.435,-0.749$, and 0.399 , respectively $(P>0.05)$. Therefore, the sensitivities of $S$. sclerotiorum isolates to benzothiostrobin were not positively correlated with their sensitivities to iprodione,

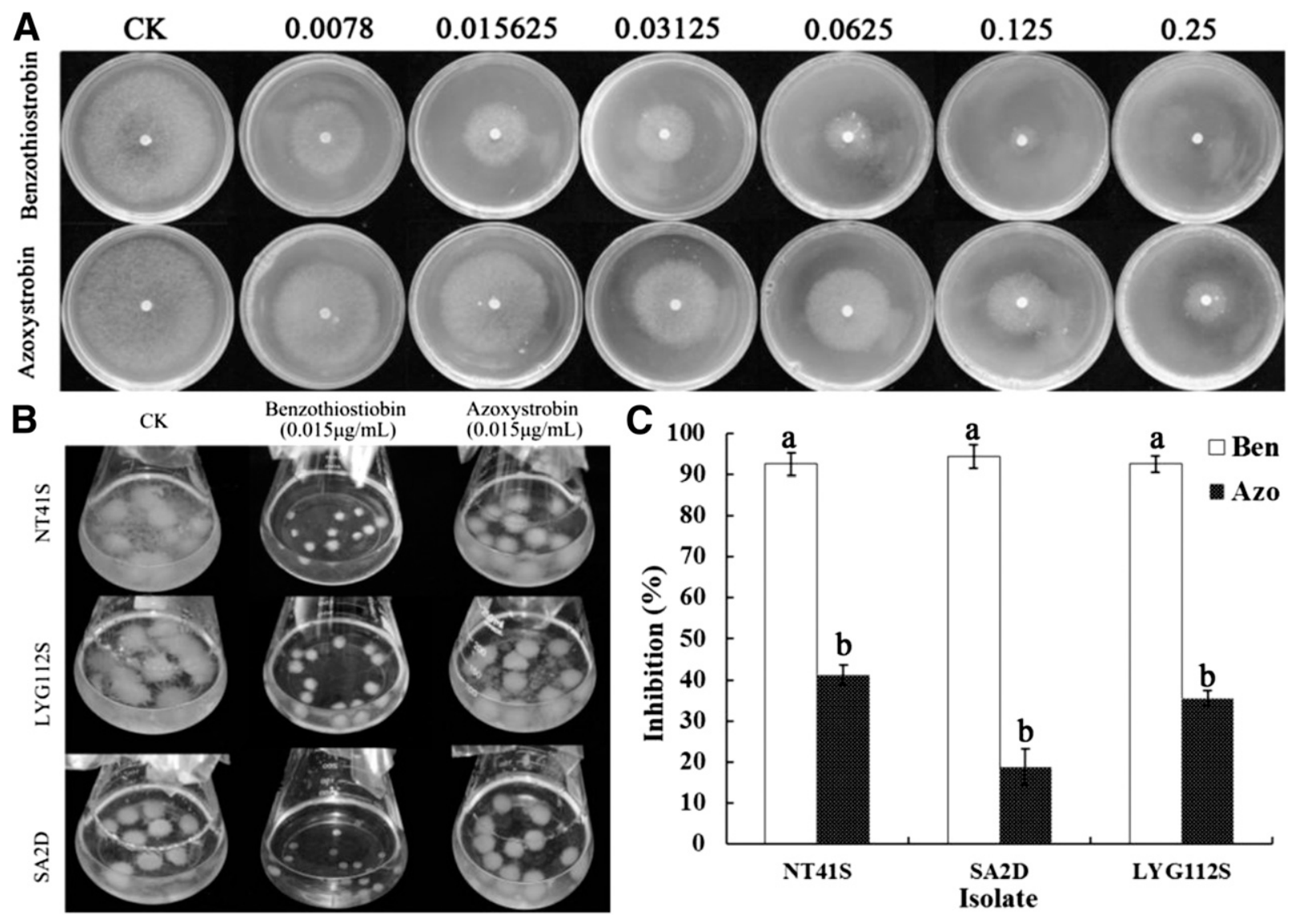

Fig. 2. Effect of benzothiostrobin and azoxystrobin on mycelial growth of Sclerotinia sclerotiorum. Note that all results presented in this figure were derived with addition of salicylhydroxamic acid. A, Mycelial growth on agar. Fungicide concentrations ( $\mu \mathrm{g} / \mathrm{ml})$ are listed along the top. Plates of a representative isolate (WX7S) were photographed after 2 days of culture. B, Mycelial growth in shake culture. Isolates are listed on the left and fungicide concentrations are listed at the top. Flasks were photographed after 3 days of culture. $\mathbf{C}$, Inhibition of mycelial growth in shake culture. Fungicide rates were the same as in B. The inhibition rate is based on dry weight of the mycelium relative to that of the control. Values are means \pm standard errors of two experiments. For a given isolate, bars with the same letter are not significantly different according to Fisher's least significant difference test $(P=0.05)$.

Table 3. Inhibition of sclerotial germination of Sclerotinia sclerotiorum by benzothiostrobin (Ben) and azoxystrobin (Azo)

\begin{tabular}{|c|c|c|c|c|c|c|}
\hline \multirow[b]{2}{*}{ Fungicide } & \multicolumn{3}{|c|}{ Inhibition (\%) of SA2D sclerotial germination } & \multicolumn{3}{|c|}{ Inhibition (\%) of LYG112S sclerotial germination } \\
\hline & 3 days & 4 days & 5 days & 3 day & 4 days & 5 days \\
\hline $\operatorname{Ben}(0.5 \mu \mathrm{g} / \mathrm{ml})$ & $78 \pm 12 b$ & $53 \pm 12 c$ & $14 \pm 9 \mathrm{e}$ & $47 \pm 12 \mathrm{~cd}$ & $46 \pm 11 \mathrm{c}$ & $18 \pm 8 d$ \\
\hline $\operatorname{Ben}(1 \mu \mathrm{g} / \mathrm{ml})$ & $100 \mathrm{a}$ & $85 \pm 5 b$ & $17 \pm 4$ de & $68 \pm 18 \mathrm{bc}$ & $49 \pm 15 c$ & $44 \pm 10 \mathrm{c}$ \\
\hline Ben $(2 \mu \mathrm{g} / \mathrm{ml})$ & $100 \mathrm{a}$ & $92 \pm 8 \mathrm{ab}$ & $38 \pm 13 \mathrm{c}$ & $85 \pm 14 \mathrm{ab}$ & $75 \pm 24 b$ & $56 \pm 10 \mathrm{bc}$ \\
\hline Ben $(5 \mu \mathrm{g} / \mathrm{ml})$ & $100 \mathrm{a}$ & $100 \mathrm{a}$ & $80 \pm 9 a b$ & $100 \mathrm{a}$ & $95 \pm 5 \mathrm{a}$ & $82 \pm 4 \mathrm{a}$ \\
\hline Azo $(0.5 \mu \mathrm{g} / \mathrm{ml})$ & $81 \pm 12 b$ & $64 \pm 5 c$ & $17 \pm 4$ de & $39 \pm 13 d$ & $37 \pm 12 \mathrm{c}$ & $16 \pm 8 \mathrm{~d}$ \\
\hline Azo $(1 \mu \mathrm{g} / \mathrm{ml})$ & $93 \pm 7 \mathrm{ab}$ & $81 \pm 11 b$ & $31 \pm 13 \mathrm{~cd}$ & $54 \pm 19 \mathrm{~cd}$ & $52 \pm 14 \mathrm{c}$ & $49 \pm 8 b c$ \\
\hline Azo $(2 \mu \mathrm{g} / \mathrm{ml})$ & $100 \mathrm{a}$ & $90 \pm 10 a b$ & $76 \pm 6 b$ & $852 \pm 14 a b$ & $78 \pm 23 a b$ & $60 \pm 13 b$ \\
\hline Azo $(5 \mu \mathrm{g} / \mathrm{ml})$ & $100 \mathrm{a}$ & $100 \mathrm{a}$ & $93 \pm 1 \mathrm{a}$ & $100 \mathrm{a}$ & $93 \pm 7 \mathrm{ab}$ & $89 \pm 4 a$ \\
\hline
\end{tabular}

${ }^{\mathrm{z}}$ Inhibition was assessed for two isolates (SA2D and LYG112S) after 3, 4, and 5 days on agar. All plates contained salicylhydroxamic acid at $50 \mu \mathrm{g} / \mathrm{ml}$. Inhibition was calculated relative to control plates that did not contain Ben or Azo. Values are the means ( \pm standard deviations) of two independent experiments, each with three replications per treatment. Means in a column followed by the same letter are not significantly different according to Fisher's least significant difference test $(P=0.05)$. 
fludioxonil, boscalid, or carbendazim. In other words, crossresistance between benzothiostrobin and these other fungicides was not detected.

Synergistic interaction between benzothiostrobin and fluazinam against isolate WX1S. Depending on the ratio of the fungicides in the mixture, inhibition of mycelial growth of isolate WX1S after $48 \mathrm{~h}$ on agar differed among mixtures of benzothiostrobin and fluazinam (Table 6). The $\mathrm{EC}_{50}$ value was numerically smallest, with the 1:1 ratio, although this value was not statistically different from that obtained with ratios of $6: 1$ (benzothiostrobin/fluazinam), 4:1, or 2:1. The SR values indicated that inhibition by benzothiostrobin/fluazinam at 4:1, 2:1, and 1:1 was synergistic. Mixtures at 6:1, 1:2 1:4, and 1:6 had additive effects (Table 6).

At a 1:1 ratio of benzothiostrobin to fluazinam, which was the optimal ratio against isolate WX1S (Table 6), the $\mathrm{EC}_{50}$ values of six S. sclerotiorum isolates ranged from 0.0034 to $0.0094 \mu \mathrm{g} / \mathrm{ml}$, with a mean of $0.0062 \mu \mathrm{g} / \mathrm{ml}$ (Table 7). The SR values indicated that the interaction was synergistic for all six isolates of $S$. sclerotiorum (Table 7).

Inhibition of mycelial growth of isolate WX1S over time by a 1:1 mixture of benzothiostrobin and fluazinam. The inhibition of mycelial growth was greater with benzothiostrobin than with fluazinam at $0.01 \mu \mathrm{g} / \mathrm{ml}$ at 12 and $54 \mathrm{~h}$. The inhibition was greater with the mixture than with benzothiostrobin alone at $54 \mathrm{~h}$. However, the mixture was less effective than benzothiostrobin alone at $12 \mathrm{~h}$. This may be because benzothiostrobin worked earlier than fluazinam against $S$. sclerotiorum (Fig. 3).

Control of Sclerotinia stem rot by benzothiostrobin alone and a 1:1 mixture of benzothiostrobin and fluazinam in the field. Results from both field experiments were similar and have been independently presented (Table 8 ). The mean disease incidence in control plots were $43.7 \%$, while application of benzothiostrobin and the mixture at $150 \mathrm{~g}$ a.i. $\mathrm{ha}^{-1}$ reduced the mean incidence by 54 and $69.9 \%$, respectively (data not shown). The level of control

Table 4. Control of Sclerotinia sclerotiorum by benzothiostrobin and azoxystrobin on detached rapeseed leaves ${ }^{\mathrm{z}}$

\begin{tabular}{lccc}
\hline Treatment & Lesion diameter $(\mathbf{c m})$ & Lesion area $\left(\mathbf{c m}^{2}\right)$ & Control $(\boldsymbol{\%})$ \\
\hline Ben $(5 \mu \mathrm{g} / \mathrm{ml})$ & $2.27 \pm 0.14 \mathrm{ab}$ & $4.05 \pm 0.50 \mathrm{~b}$ & $31 \pm 3 \mathrm{c}$ \\
Ben $(10 \mu \mathrm{g} / \mathrm{ml})$ & $1.87 \pm 0.17 \mathrm{bc}$ & $2.75 \pm 0.48 \mathrm{bc}$ & $53 \pm 1 \mathrm{~b}$ \\
Ben $(20 \mu \mathrm{g} / \mathrm{ml})$ & $1.51 \pm 0.22 \mathrm{c}$ & $1.81 \pm 0.53 \mathrm{~cd}$ & $68 \pm 14 \mathrm{ab}$ \\
Ben $(40 \mu \mathrm{g} / \mathrm{ml})$ & $0.98 \pm 0.05 \mathrm{~d}$ & $0.76 \pm 0.07 \mathrm{~d}$ & $87 \pm 3 \mathrm{a}$ \\
Azo $(20 \mu \mathrm{g} / \mathrm{ml})$ & $1.69 \pm 0.23 \mathrm{c}$ & $2.26 \pm 0.61 \mathrm{~cd}$ & $60 \pm 17 \mathrm{~b}$ \\
$0.1 \%$ Tween 80 & $2.73 \pm 0.24 \mathrm{a}$ & $5.91 \pm 1.01 \mathrm{a}$ & $\ldots$ \\
\hline
\end{tabular}

z Values are means ( \pm standard deviations) of three experiments. Means followed by the same letter are not significantly different according to Fisher's least significant difference test $(P=0.05)$. obtained with the $1: 1$ mixture at $150 \mathrm{~g}$ a.i. $\mathrm{ha}^{-1}$ did not significantly differ from that obtained with benzothiostrobin alone at $150 \mathrm{~g}$ a.i. $\mathrm{ha}^{-1}(P>0.05)$. Iprodione (the standard) also controlled the disease but not well as benzothiostrobin alone and the mixture $(P<0.05)$.

\section{Discussion}

The fungus $S$. sclerotiorum that is the causative agent of Sclerotinia stem rot has developed resistance to benzimidazole and dicarboximide fungicides worldwide, and high levels of resistance to these fungicides had developed in the field $(19,25)$. Because of these pesticide resistance problems, novel alternative fungicides should be used for managing Sclerotinia stem rot. Therefore, we determined the effects of the novel fungicide benzothiostrobin on S. sclerotiorum in the laboratory and on Sclerotinia stem rot in rape fields.

When combined with SHAM in the current study, the novel fungicide benzothiostrobin had higher activity against mycelial growth of $S$. sclerotiorum than the standard, azoxystrobin. Benzothiostrobin also exhibited excellent antifungal activity on detached rapeseed leaves.

Because sclerotia of $S$. sclerotiorum serve as the primary survival structures and inoculum sources during seasonal crop infection cycles $(1,26,33)$, sclerotia are crucial in the life cycle of $S$. sclerotiorum.

Table 6. Synergistic effects of mixtures of benzothiostrobin (Ben) and fluazinam (Flu) on mycelial growth of Sclerotinia sclerotiorum (isolate WX1S) as indicated by $\mathrm{EC}_{50}$ values ${ }^{\mathrm{w}}$

\begin{tabular}{lccc}
\hline Fungicide & $\mathbf{E C}_{\mathbf{5 0}(\mathbf{m e})}(\boldsymbol{\mu g} / \mathbf{m l})^{\mathbf{x}}$ & $\mathbf{E C}_{\mathbf{5 0}(\mathrm{th})}(\boldsymbol{\mu g} / \mathbf{m l})^{\mathbf{y}}$ & $\mathbf{S R}^{\mathbf{z}}$ \\
\hline Ben alone & $0.0111 \pm 0.0008 \mathrm{cde}$ & - & - \\
Flu alone & $0.0129 \pm 0.0030 \mathrm{~cd}$ & - & -
\end{tabular}

Ben:Flu (6:1) $\quad 0.0089 \pm 0.0021$ def $\quad 0.0113 \pm 0.0004$ a $1.2872 \pm 0.2481 \mathrm{c}$ Ben:Flu (4:1) $\quad 0.0048 \pm 0.0006 \mathrm{f} \quad 0.0113 \pm 0.0002$ a $\quad 2.3818 \pm 0.3305$ a Ben:Flu (2:1) $\quad 0.0064 \pm 0.0002$ ef $\quad 0.0115 \pm 0.0002$ a $\quad 1.7883 \pm 0.0898 \mathrm{~b}$ Ben:Flu (1:1) $\quad 0.0042 \pm 0.0001 \mathrm{f} \quad 0.0118 \pm 0.0008$ a $\quad 2.7735 \pm 0.1404 \mathrm{a}$ Ben:Flu (1:2) $0.0149 \pm 0.0034$ bc $\quad 0.0121 \pm 0.0014$ a $\quad 0.8227 \pm 0.0906 \mathrm{~d}$ Ben:Flu (1:4) $0.0188 \pm 0.0018 \mathrm{ab} \quad 0.0124 \pm 0.0020$ a $\quad 0.6553 \pm 0.0453 \mathrm{~d}$ Ben:Flu (1:6) $\quad 0.0226 \pm 0.0052$ a $\quad 0.0125 \pm 0.0023$ a $\quad 0.5561 \pm 0.0264 \mathrm{~d}$

w Values are means ( \pm standard deviations). Means in a column followed by different letters are not significantly $(P=0.05)$ different according to Fisher's least significant difference test; - indicates no data.

${ }^{x} \mathrm{EC}_{50}=$ effective concentration causing $50 \%$ mycelial growth inhibition . $\mathrm{EC}_{50(\mathrm{me})}$ indicates the measured $\mathrm{EC}_{50}$ values of the fungicides.

${ }^{y} \mathrm{EC}_{50(\mathrm{th})}$ indicates the theoretical $\mathrm{EC}_{50}$ values of the mixtures.

${ }^{\mathrm{z}}$ Synergy ratio $(\mathrm{SR})=$ ratio between expected and observed $\mathrm{EC}_{50}$ values. $\mathrm{SR}=$ $\mathrm{EC}_{50}(\mathrm{th}) / \mathrm{EC}_{50}$ (me). An SR $<0.5$ indicates an antagonistic interaction between the fungicides, an SR between 0.5 and 1.5 indicates an additive interaction, and an SR $>1.5$ indicates a synergistic interaction.

Table 5. Sensitivity of four other fungicide-sensitive and -resistant Sclerotinia sclerotiorum strains to benzothiostrobin ${ }^{\mathrm{z}}$

\begin{tabular}{|c|c|c|c|c|c|}
\hline \multirow[b]{2}{*}{ Isolate } & \multicolumn{5}{|c|}{$\mathrm{EC}_{50}(\mu \mathrm{g} / \mathrm{ml})$} \\
\hline & Benzothiostrobin & Iprodione & Fludioxonil & Boscalid & Carbendazim \\
\hline JK19 & $0.0179 \pm 0.0075 a b c$ & $0.2684 \pm 0.0035 \mathrm{c}$ & $0.0146 \pm 0.0011 \mathrm{c}$ & $0.2677 \pm 0.0223 b$ & $0.1534 \pm 0.0047 b$ \\
\hline NT16 & $0.0195 \pm 0.0035 \mathrm{abc}$ & $0.3054 \pm 0.0163 b$ & $0.0189 \pm 0.0014 b$ & $0.2683 \pm 0.0284 b$ & $0.1565 \pm 0.0504 \mathrm{~b}$ \\
\hline SZ10S & $0.0112 \pm 0.0005 b c$ & $0.1835 \pm 0.0106 \mathrm{~d}$ & $0.014 \pm 0.0002 \mathrm{c}$ & $0.3247 \pm 0.0520 b$ & $0.1088 \pm 0.0191 b$ \\
\hline HA61S & $0.0172 \pm 0.0045 \mathrm{abc}$ & $0.2749 \pm 0.0058 \mathrm{c}$ & $0.0092 \pm 0.0016 \mathrm{~d}$ & $0.2936 \pm 0.0873 b$ & $0.1044 \pm 0.0132 b$ \\
\hline JK19R1 & $0.0045 \pm 0.0019 \mathrm{c}$ & - & - & $>30 \mathrm{a}$ & - \\
\hline NT16R1 & $0.0074 \pm 0.0035 b c$ & - & - & $>30 a$ & - \\
\hline JK19R2 & $0.0103 \pm 0.0042 b c$ & - & - & $>30 \mathrm{a}$ & - \\
\hline ZJ288-1 & $0.0200 \pm 0.0023 \mathrm{abc}$ & $>100 \mathrm{a}$ & - & - & - \\
\hline CZ138-1 & $0.0196 \pm 0.0094 \mathrm{abc}$ & $>100 \mathrm{a}$ & - & - & - \\
\hline SZ10R & $0.0122 \pm 0.0007 \mathrm{bc}$ & - & $>100 \mathrm{a}$ & - & - \\
\hline HA61R & $0.0323 \pm 0.0248 \mathrm{a}$ & - & $>100 \mathrm{a}$ & - & - \\
\hline HA4D & $0.0202 \pm 0.0059 a b c$ & - & - & - & $>100 \mathrm{a}$ \\
\hline XH17D & $0.0239 \pm 0.0078 \mathrm{ab}$ & - & - & - & $>100 \mathrm{a}$ \\
\hline
\end{tabular}

z Values are means ( \pm standard deviations) of three experiments. Means followed by the same letter are not significantly different according to Fisher's least significant difference test $(P=0.05)$; - indicates no data. 
Sclerotia germinate and form long-stalked apothecia. These apothecia release large numbers of ascospores, which are the main source of inoculum for infecting susceptible plants (22). However, the eruptive germination of sclerotia followed by mycelial growth also causes stem rot in rapeseed fields. Therefore, suppression of sclerotial germination and subsequent mycelial growth should reduce the ability of the pathogen to cause disease in the field. We found that benzothiostrobin could inhibit sclerotial germination and that inhibition by benzothiostrobin was comparable with inhibition by azoxystrobin. Higher concentrations of benzothiostrobin were required to inhibit sclerotial germination than to inhibit mycelial growth. This is in agreement with many reports that indicated that sclerotia are usually less sensitive than mycelium to fungicides (4). At lower concentrations, benzothiostrobin inhibition of sclerotial germination but not of mycelial growth declined with time.

Generally, analysis of cross-resistance between a fungicide and other fungicides should use resistant mutants of the fungicide and the parent strains. However, our efforts to induce benzothiostrobin-resistant mutants of S. sclerotiorum have been unsuccessful. Therefore, we used the resistant mutants and sensitive strains of other commonly used fungicides for our analysis of cross-resistance to benzothiostrobin. No cross-resistance was detected, probably because benzothiostrobin and the other commonly used fungicides have different modes of action

Table 7. Synergistic effects of a 1:1 mixture of benzothiostrobin and fluazinam on mycelial growth of six isolates of Sclerotinia sclerotiorum ${ }^{\mathrm{y}}$

\begin{tabular}{lcccc}
\hline Isolate & $\mathbf{E C}_{\mathbf{5 0}}(\boldsymbol{\mu} \mathbf{g} / \mathbf{m l})$ of benzothiostrobin & $\mathbf{E C}_{\mathbf{5 0}}(\boldsymbol{\mu} \mathbf{g} / \mathbf{m l})$ of fluazinam & $\mathbf{E C}_{\mathbf{5 0}}(\boldsymbol{\mu g} / \mathbf{m l})$ of the mixture & $\mathbf{S R}^{\mathbf{z}}$ \\
\hline XH8D & $0.0115 \pm 0.0005$ & $0.0153 \pm 0.0006$ & $0.0069 \pm 0.0021$ & $2.0048 \pm 0.6933$ \\
YZ10S & $0.0198 \pm 0.0052$ & $0.0159 \pm 0.0010$ & $0.0079 \pm 0.0002$ & $1.2080 \pm 0.3925$ \\
NT28S & $0.009 \pm 0.0016$ & $0.0095 \pm 0.0008$ & $0.0053 \pm 0.0006$ & $2.2951 \pm 0.1189$ \\
LYG112S & $0.0399 \pm 0.0024$ & $0.0143 \pm 0.0008$ & $0.0094 \pm 0.0021$ & $2.4780 \pm 0.8432$ \\
SA2D & $0.0079 \pm 0.0023$ & $0.0086 \pm 0.0023$ & $0.0034 \pm 0.0002$ & $2.4434 \pm 0.2559$ \\
WX7S & $0.0121 \pm 0.0006$ & $0.0101 \pm 0.0006$ & $0.0045 \pm 0.0004$ &
\end{tabular}

${ }^{\mathrm{y}} \mathrm{EC}_{50}=$ effective concentration causing $50 \%$ mycelial growth inhibition. Values are means ( \pm standard deviations).

${ }^{z}$ Synergy ratio $=$ ratio between expected and observed $\mathrm{EC}_{50}$ values. An SR > 1.5 indicates a synergistic interaction.

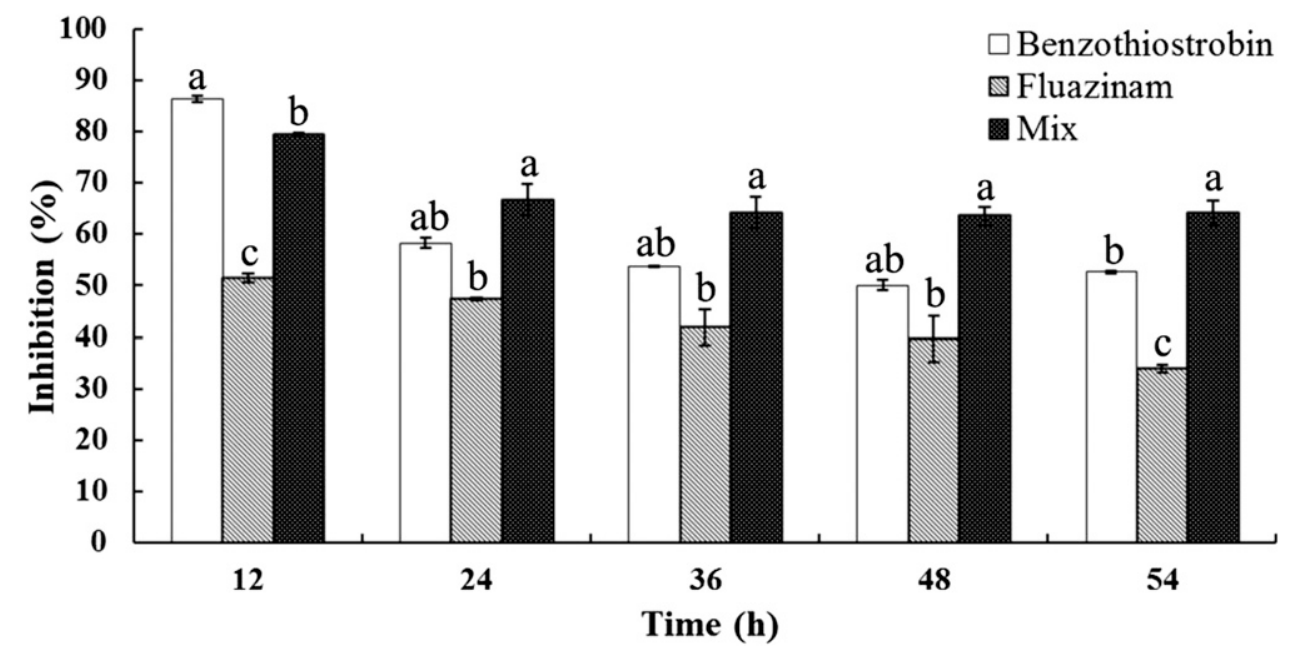

Fig. 3. Inhibition of growth (\%) of isolate WX1S in alkyl ester agar medium containing benzothiostrobin alone at $0.01 \mu \mathrm{g} / \mathrm{ml}$, fluazinam alone at $0.01 \mu \mathrm{g} / \mathrm{ml}$, or a $1: 1 \mathrm{mixture}$ of benzothiostrobin and fluazinam at $0.01 \mu \mathrm{g} / \mathrm{ml}$. Salicylhydroxamic acid (SHAM) at $50 \mu \mathrm{g} / \mathrm{ml}$ was added to all treatments except the treatments of fluazinam. Inhibition was calculated relative to a control that contained SHAM or not but did not contain benzothiostrobin or fluazinam. Values are means \pm standard errors of two experiments. At each time, bars with different letters are significantly different according to Fisher's least significant difference test $(P=0.05)$.

Table 8. Median disease rating (MDR), mean rank $\left(\boldsymbol{R}_{i j}\right)$, and relative treatment effects $\left(\widehat{\boldsymbol{p}}_{i j}\right)$ along with $95 \%$ confidence intervals (CI) for benzothiostrobin (Ben) alone and a 1:1 mixture of Ben and fluazinam (Flu) on the control of Sclerotinia stem rot of rape in the field ${ }^{\mathrm{y}}$

\begin{tabular}{|c|c|c|c|c|c|c|c|c|c|}
\hline \multirow[b]{2}{*}{ Treatment $^{\mathrm{z}}$} & \multirow[b]{2}{*}{ Dosage (g a.i. $\mathrm{ha}^{-1}$ ) } & \multicolumn{4}{|c|}{ Field 1} & \multicolumn{4}{|c|}{ Field 2} \\
\hline & & MDR & $\boldsymbol{R}_{i j}$ & $\widehat{p}_{i j}$ & $95 \%$ CI for $\widehat{p}_{i j}$ & MDR & $R_{i j}$ & $\widehat{p}_{i j}$ & $95 \%$ CI for $\widehat{p}_{i j}$ \\
\hline $5 \%$ Ben (EC) & 75 & 1.00 & 21.67 & 0.64 & $(0.49,0.77)$ & 1.00 & 22.17 & 0.67 & $(0.47,0.80)$ \\
\hline $5 \%$ Ben (EC) & 112.5 & 0.50 & 16.33 & 0.48 & $(0.25,0.72)$ & 0.00 & 19.33 & 0.57 & $(0.39,0.73)$ \\
\hline $5 \%$ Ben $(\mathrm{EC})$ & 150 & 0.00 & 13.33 & 0.39 & $(0.17,0.69)$ & 0.00 & 13.33 & 0.39 & $(0.15,0.71)$ \\
\hline $40 \%$ Flu (SC) & 75 & 1.00 & 18.67 & 0.55 & $(0.27,0.79)$ & 1.00 & 19.17 & 0.57 & $(0.26,0.82)$ \\
\hline $40 \%$ Flu (SC) & 112.5 & 0.50 & 16.33 & 0.48 & $(0.25,0.72)$ & 0.50 & 16.33 & 0.48 & $(0.24,0.73)$ \\
\hline $40 \%$ Flu (SC) & 150 & 0.00 & 13.33 & 0.39 & $(0.17,0.69)$ & 0.00 & 13.33 & 0.39 & $(0.15,0.71)$ \\
\hline Ben:Flu (1:1) & 75 & 0.00 & 13.33 & 0.39 & $(0.17,0.69)$ & 0.00 & 13.33 & 0.39 & $(0.15,0.71)$ \\
\hline Ben:Flu (1:1) & 112.5 & 0.00 & 8.00 & 0.23 & $(0.17,0.31)$ & 0.00 & 7.50 & 0.21 & $(0.16,0.29)$ \\
\hline Ben:Flu (1:1) & 150 & 0.00 & 8.00 & 0.23 & $(0.17,0.31)$ & 0.00 & 7.50 & 0.21 & $(0.16,0.29)$ \\
\hline $50 \% \operatorname{Ipr}(\mathrm{WP})$ & 150 & 1.00 & 26.33 & 0.78 & $(0.63,0.87)$ & 1.00 & 25.00 & 0.74 & $(0.65,0.81)$ \\
\hline Water (check) & $\ldots$ & 3.00 & 31.67 & 0.94 & $(0.87,0.95)$ & 3.00 & 30.00 & 0.89 & $(0.61,0.95)$ \\
\hline
\end{tabular}

${ }^{\mathrm{y}}$ MDR $=$ severity of Sclerotinia stem rot assessed visually on an ordinal 0-to-9 scale, where $0=$ no lesions and $9=$ lesions on $>50 \%$ of the stem.

${ }^{\mathrm{z}} \mathrm{Ipr}=$ iprodione. 
(16). Because of the limitation of resistant isolates provided by our lab, further work with a larger number of isolates is needed.

Fungicides may provide better disease control when used in combinations than alone $(8,21)$. Azoxystrobin and thiram, for example, have synergistic effects against $S$. sclerotiorum (10). In this study, we found that a 1:1 mixture of benzothiostrobin and fluazinam resulted in a strong synergistic inhibition of mycelial growth of S. sclerotiorum isolates.

Management of insensitivity development depends on an integrated pest management (IPM) approach, including cultural practices and resistant cultivars as well as chemical and biological control. As an important approach of IPM, the reduction of selection pressure is accomplished by restricting the use of fungicides with the same or a similar mode of action, by alternating fungicides that differ in mode of action, and by using mixtures of fungicides which differ in mode of action. The results in this study showed that the application of benzothiostrobin alone at $150 \mathrm{~g}$ a.i. $\mathrm{ha}^{-1}$ or a 1:1 mixture of benzothiostrobin and fluazinam at $150 \mathrm{~g}$ a.i. $\mathrm{ha}^{-1}$ was more effective than iprodione in controlling Sclerotinia stem rot in the field.

In conclusion, the current study demonstrates that benzothiostrobin or the mixture of benzothiostrobin and fluazinam at the ratio of 1:1 greatly inhibits mycelial growth of $S$. sclerotiorum in vitro and provides good control of Sclerotinia stem rot in the field. We also found that benzothiostrobin inhibits the germination of sclerotia in vitro and has no cross-resistance with other common fungicides. Therefore, benzothiostrobin combined with fluazinam or alternated with other fungicides will be a valuable tool for controlling Sclerotinia stem rot and for limiting the development of fungicide resistance.

\section{Acknowledgments}

This study was supported by the Commonweal Specialized Research Fund of China Agriculture (201303023) and the open fund of Key Laboratory of Pesticide and Chemical Biology of Ministry of Education (201301A03).

\section{Literature Cited}

1. Adams, P., and Ayers, W. 1979. Ecology of Sclerotinia species. Phytopathology 69:896-899.

2. Anema, B., Bouwman, J., Komyoji, T., and Suzuki, K. 1992. Pages 663-668 in: Fluazinam: A Novel Fungicide for Use Against Phytophthora infestans in Potatoes. British Crop Protection Council, Farnham, UK

3. Anke, T. 1995. The antifungal strobilurins and their possible ecological role. Can. J. Bot. 73:940-945.

4. Baker, K., and Cook, R. J. 1974. Page 433 in: Biological Control of Plant Pathogens. W. H. Freeman and Company, USA.

5. Bardin, S., and Huang, H. 2001. Research on biology and control of Sclerotinia diseases in Canada. Can. J. Plant Pathol. 23:88-98.

6. Bartlett, D. W., Clough, J. M., Godwin, J. R., Hall, A. A., Hamer, M., and ParrDobrzanski, B. 2002. The strobilurin fungicides. Pest Manag. Sci. 58:649-662.

7. Boland, G., and Hall, R. 1994. Index of plant hosts of Sclerotinia sclerotiorum. Can. J. Plant Pathol. 16:93-108.

8. Caldiz, D., Rolon, D., Di Rico, J., and Andreu, A. 2007. Performance of dimethomorph + mancozeb applied to seed potatoes in early management of late blight (Phytophthora infestans). Potato Res. 50:59-70.

9. Duan, Y. B., Ge, C. Y., and Zhou, M. G. 2014. Molecular and biochemical characterization of Sclerotinia sclerotiorum laboratory mutants resistant to dicarboximide and phenylpyrrole fungicides. J. Pest Sci. 87:221-230.

10. Duan, Y. B., Liu, S. M., Ge, C. Y., Feng, X. J., Chen, C. J., and Zhou, M. G. 2012. In vitro inhibition of Sclerotinia sclerotiorum by mixtures of azoxystrobin, SHAM, and thiram. Pestic. Biochem. Physiol. 103:101-107.

11. Fungicide Resistance Action Committee. 2011. FRAC Code List: Fungicides sorted by mode of action (including FRAC Code numbering). CropLife International, Brussels. Online publication. http://www.frac.info

12. Gisi, U., Binder, H., and Rimbach, E. 1985. Synergistic interactions of fungicides with different modes of action. Trans. Br. Mycol. Soc. 85:299-306.
13. Goussous, S. J., Mas'ad, I. S., Abu El-Samen, F. M., and Tahhan, R. A. 2013. In vitro inhibitory effects of rosemary and sage extracts on mycelial growth and sclerotial formation and germination of Sclerotinia sclerotiorum. Arch. Phytopathol. Plant Prot. 46:890-902.

14. Kuang, J., Hou, Y. P., Wang, J. X., and Zhou, M. G. 2011. Sensitivity of Sclerotinia sclerotiorum to fludioxonil: In vitro determination of baseline sensitivity and resistance risk. Crop Prot. 30:876-882.

15. Kurt, Ş., Güneş, U., and Soylu, E. M. 2011. In vitro and in vivo antifungal activity of synthetic pure isothiocyanates against Sclerotinia sclerotiorum. Pest Manag. Sci. 67:869-875.

16. Leroux, P., Chapeland, F., Desbrosses, D., and Gredt, M. 1999. Patterns of cross-resistance to fungicides in Botryotinia fuckeliana (Botrytis cinerea) isolates from French vineyards. Crop Prot. 18:687-697.

17. Li, G., Huang, H., Miao, H., Erickson, R., Jiang, D., and Xiao, Y. 2006. Biological control of Sclerotinia diseases of rapeseed by aerial applications of the mycoparasite Coniothyrium minitans. Eur. J. Plant Pathol. 114:345 355.

18. Li, H. X., Lu, Y. J., Zhou, M. G., and Wang, X. F. 2003. Mutation in $\beta$-tubulin of Sclerotinia sclerotiorum conferring resistance to carbendazim in rapeseed field isolate. Chin. J. Oil Crop Sci. 25:56-60.

19. Ma, H. X., Chen, Y., Wang, J. X., Yu, W. Y., Tang, Z. H., Chen, C. J., and Zhou, M. G. 2009. Activity of carbendazim, dimethachlon, iprodione, procymidone and boscalid against Sclerotinia stem rot in Jiangsu Province of China. Phytoparasitica 37:421-429.

20. Ma, H. X., Feng, X. J., Chen, Y., Chen, C. J., and Zhou, M. G. 2009. Occurrence and characterization of dimethachlon insensitivity in Sclerotinia sclerotiorum in Jiangsu Province of China. Plant Dis. 93:36-42.

21. Platt, H. 1985. Controlling potato late blight with systemic-protectant fungicide combinations of metalaxyl and mancozeb. Am. Potato J. 62 499-510.

22. Purdy, L. 1979. Sclerotinia sclerotiorum: History, diseases, symptomatology, host range, geographic distribution, and impact. Phytopathology 69:875-880

23. Rebollar-Alviter, A., Madden, L., Jeffers, S., and Ellis, M. 2007. Baseline and differential sensitivity to two QoI fungicides among isolates of Phytophthora cactorum that cause leather rot and crown rot on strawberry. Plant Dis. 91: 1625-1637.

24. Shah, D. A., and Madden, L. V. 2004. Nonparametric analysis of ordinal data in designed factorial experiments. Phytopathology 94:33-43.

25. Shi, Z. Q., Zhou, M. G., and Ye, Z. Y. 1999. Resistance of Sclerotinia sclerotiorum to carbendazim and dimethachlon. Chin. J. Oil Crop Sci. 22 54-57, 61.

26. Smolinska, U., and Horbowicz, M. 1999. Fungicidal activity of volatiles from selected cruciferous plants against resting propagules of soil-borne fungal pathogens. J. Phytopathol. 147:119-124.

27. Steadman, J. 1979. Control of plant diseases caused by Sclerotinia species. Phytopathology 69:904-907.

28. Thomulka, K., Abbas, C., Young, D., and Lange, J. 1996. Evaluating median effective concentrations of chemicals with bioluminescent bacteria. Bull Environ. Contam. Toxicol. 56:446-452.

29. Wadley, F. M. 1967. Pages 1-51 in: Experimental Statistics in Entomology Graduate School Press, U. S. Department of Agriculture, Washington, DC.

30. Wang, J. X., Ma, H. X., Chen, Y., Zhu, X. F., Yu, W. Y., Tang, Z. H., Chen, C. J., and Zhou, M. G. 2009. Sensitivity of Sclerotinia sclerotiorum from oilseed crops to boscalid in Jiangsu Province of China. Crop Prot. 28:882-886.

31. Wang, Y., Duan, Y. B., and Zhou, M. G. 2014. Control of Sclerotinia sclerotiorum infection in oilseed rape with strobilurin fungicide SYP-7017. Can. J. Plant Pathol. 36:354-359.

32. Wang, Y., Duan, Y. B., and Zhou, M. G. 2015. Molecular and biochemical characterization of boscalid resistance in laboratory mutants of Sclerotinia sclerotiorum. Plant Pathol. 64:101-108.

33. Willetts, H., and Bullock, S. 1992. Developmental biology of sclerotia. Mycol. Res. 96:801-816.

34. Xu, C. Y., Hou, Y. P., Wang, J. X., Liang, X. Y., and Zhou, M. G. 2014 Activity of a novel strobilurin fungicide benzothiostrobin against Sclerotinia sclerotiorum. Pestic. Biochem. Physiol. 115:32-38.

35. Yang, D. J., Wang, B., Wang, J. X., Chen, Y., and Zhou, M. G. 2009. Activity and efficacy of Bacillus subtilis strain NJ-18 against rice sheath blight and Sclerotinia stem rot of rape. Biol. Control 51:61-65.

36. Zhang, X., Sun, X., and Zhang, G. 2003. Preliminary report on the monitoring of the resistance of Sclerotinia libertinia to carbendazim and its internal management. Chin. J. Pest. Sci. Administration 24:18-22. 